\title{
Management of pregnant women in times of COVID-19 our experience from Kashmir valley
}

\author{
Syed Naseer ${ }^{1}$, Syed Uzma Andrabi ${ }^{1}$, Syed Ishfa Andrabi ${ }^{2 *}$, Humaira Tabasum ${ }^{1}$
}

\begin{abstract}
${ }^{1}$ Department of Gynaecology and Obstretrics, SKIMS Medical College, Srinagar, Kashmir, India
${ }^{2}$ Department of Biochemistry, Kashmir University, Kashmir, India
\end{abstract}

Received: 25 February 2021

Revised: 05 March 2021

Accepted: 06 March 2021

\section{*Correspondence:}

Dr. Syed Uzma Andrabi,

E-mail: uzma9559@gmail.com

Copyright: (c) the author(s), publisher and licensee Medip Academy. This is an open-access article distributed under the terms of the Creative Commons Attribution Non-Commercial License, which permits unrestricted non-commercial use, distribution, and reproduction in any medium, provided the original work is properly cited.

\section{ABSTRACT}

Background: The coronavirus disease 2019, caused by severe acute respiratory syndrome coronavirus 2 , is a global public health emergency. COVID-19 is a rapidly evolving situation, and there is limited data reporting its impact on pregnant women. Our study aimed to find the symptomatology, clinical courses and outcome of pregnant women with COVID-19 and to assess the vertical transmission potential of COVID-19 in pregnancy.

Methods: This prospective observational study was conducted at Sher-i-Kashmir Institute of Medical Sciences (SKIMS), Medical College, Department of Gynaecology and obstetrics, Srinagar from May 2020 to September 2020. All COVID-19 positive pregnant patients admitted in our institution were included in our study.

Results: The study included 100 Covid-19 positive pregnant women. Most of them were between 30 to 40 years of age. Median gestational age was 32.8 weeks. Comorbidity was present in 18 of our patients. 7 patients had gestational diabetes and 1 with overt diabetes, 5 were hypertensive, 3 had hypothyroidism, 1 with anti-phospholipid antibody syndrome (APLA) and 1 with asthma.44 patients were primigravidae and 56 were multigravidae. 27 patients delivered preterm and 44 with term pregnancy. 47 had undergone caesarean section and 24 normal vaginal delivery.88\% of our patients were asymptomatic for covid-19 disease while as 12 patients had Covid-19 disease symptoms. The main complaints reported by patients related to covid-19 disease was mild dry cough and fever (9\%). Two patients developed severe covid-19 pneumonia with ARDS and were put on ventilator, expired after 20 days of illness. All neonates were subjected to RT-PCR with none producing positive results.

Conclusions: Appropriate and timely management of Covid-19 positive pregnant women is a principle for safe motherhood and healthy offspring in times of global pandemic. The present data do not suggest an increased risk of severe disease among pregnant women. We encourage the breast feeding immediately after delivery as benefits overweigh any potential risks of virus transmission if any.

Keywords: COVID-19 disease, Pregnancy, Delivery, Perinatal outcome

\section{INTRODUCTION}

The common human coronavirus (HCoV) infections include HCoV 2, 29E9 (alpha corona virus), NL63(alpha corona virus), OC43 (Beta corona virus) and HKU1(Beta corona virus), which cause the common cold. MERS CoV (Middle East Respiratory Syndrome), SARS-CoV (Severe
Acute Respiratory Syndrome) and SARS-Cov 2 (Severe Acute Respiratory Syndrome) cause severe forms of illnesses. Novel coronavirus (SARS-CoV-2) is a new strain of corona virus causing COVID-19, first identified in Wuhan City, China in December 2019. The virus appears to have originated in Hubei province in china towards the end of 2019. Both SARS-CoV-2 and SARS- 
$\mathrm{CoV}$ are $\beta$ coronaviruses. The mortality rate of SARS-CoV infection is $10 \%$, including a mortality rate of $25 \%$ for maternal infection. ${ }^{1}$

Chinese scientists isolated the novel coronavirus from patients, sequenced the genome, and found that the genetic sequence of the virus was at least $70 \%$ similar to that of human severe acute respiratory syndrome coronavirus (SARS-CoV). The World Health Organization (WHO) named the novel coronavirus 2019-nCoV, also called severe acute respiratory syndrome coronavirus 2 (SARSCoV-2), which causes coronavirus disease 2019 (COVID19)..$^{2,3}$

On March 11th, 2020, the World Health Organisation (WHO) classified the novel coronavirus disease (COVID19), caused by the SARS-CoV-2 virus, as a global pandemic, highlighting the enormity of the viral outbreak. ${ }^{4}$ Most cases of COVID-19 globally have evidence of human-to-human transmission. This virus can be readily isolated from respiratory secretions, faeces and fomites. There are two routes by which COVID-19 can spread. The first is directly through close contact with an infected person (within 2 metres) where respiratory secretions can enter the eyes, mouth, nose or airways. This risk increases the longer someone has close contact with an infected person who has symptoms. The second route is indirectly via the touching of a surface, object or the hand of an infected person contaminated with respiratory secretions and subsequently touching one's own mouth, nose or eyes.

Understandably, this raises concerns regarding its effects during pregnancy. It has been long known that, while pregnant women are not necessarily more susceptible to viral illness, changes to their immune system during pregnancy may be associated with more severe symptoms. SARS-CoV and MERS-CoV were both known to be responsible for severe complications during pregnancy. ${ }^{5}$ However, there is no current evidence that pregnant women are more susceptible to COVID-19 infection or those with COVID-19 are more prone to develop severe pneumonia.

Viral pneumonia is one of the leading causes of pregnancy deaths worldwide. $^{6}$ Physiological changes during pregnancy, such as reduced functional residual volumes, diaphragm elevation, and oedema of respiratory tract mucosa, as well as changes in cell immunity can lead to increased susceptibility to viral infections and can have worsened outcomes. ${ }^{7}$ However, to date, there are limited studies pertaining to the outcomes of COVID-19 during pregnancy, differences in clinical course, and the potential risks to the unborn child. Studies have so far shown that the clinical, radiological, and laboratory characteristics of COVID-19 pneumonia in pregnant women are similar to those reported for nonpregnant patients. ${ }^{8-13}$ Moreover, currently there has been no evidence of intrauterine vertical transmission of SARS-CoV-2 infection in pregnant women with COVID-19. ${ }^{8-13}$ This study aimed with an objective to find the symptomatology, clinical courses and outcomes of pregnant women with COVID19 disease, and to assess the vertical transmission potential of COVID-19 in pregnancy.

\section{METHODS}

\section{Study design}

Prospective observational study.

\section{Study area}

The study was conducted at Sher-i-Kashmir Institute of Medical Sciences (SKIMS), Medical College Bemina, Department of Gynaecology and obstetrics, Srinagar.

\section{Study period}

The study was conducted from May 2020 to September 2020.

\section{Inclusion criteria}

All COVID-19 positive pregnant patients admitted in SKIMS Medical College and Hospital, Bemina, Srinagar were included in our study.

Our institute was designated as COVID-19 Hospital in the Valley of Kashmir in April 2020. All the patients included in our study were confirmed cases of COVID -19 positive by RT-PCR. After thorough history and clinical/obstetric examination, all our patients were subjected to following investigations- complete blood count, kidney/liver function test/blood sugar, VBG and electrolytes/ electocardiography, ultrasonography abdomen and pelvisfor foetal wellbeing and obstetric parameters, cardiotocography when needed.

All the patients were managed depending upon the clinical course of disease and trimester of pregnancy. Patients were strictly monitored for COVID-19 symptomatology. Viral clearance was confirmed by RT-PCR using throat swab samples before discharge. Discharge of neonate and the mother was planned once both of them turned COVID-19 negative and were stable.

Women with mild disease were subjected to general fluidelectrolyte balance and symptomatic treatment along with close vigilant maternal vitals surveillance. Monitoring for secondary bacterial infection and timely use of antibiotics when indicated was stressed upon.

\section{Statistical analysis}

The recorded data was compiled and entered in a spreadsheet (Microsoft Excel) and then exported to data editor of Statistical package for social sciences (SPSS) Version 20.0 (SPSS Inc., Chicago, Illinois, USA). Continuous variables were expressed as mean \pm SD and 
categorical variables were summarized as frequencies and percentages.

\section{RESULTS}

Total of 100 covid-19 positive pregnant women were entitled in our study. Most of them were between 30 to 40 years of age. Mean age was 32.5 years (Table 1). Median gestational age was 32.8 weeks including 1 patient in first trimester, 3 in second trimester and 96 in third trimester (Table 2). Medical co-morbidies were present in 18 of our patients. 8 patients had diabetes $(7$ with gestational diabetes, 1 with overt diabetes), 5 were hypertensive, 3 had hypothyroidism, 1 with anti-phospholipid antibody syndrome (APLA) and 1 with bronchial asthma. 44 patients were primigravidae and 56 were multigravidae.

Table 1: Age distribution.

\begin{tabular}{|lll|}
\hline Age (in years) & Number & Percentage \\
\hline $\mathbf{2 0 - 3 0}$ & 25 & 25 \\
\hline $\mathbf{3 0 - 4 0}$ & 75 & 75 \\
\hline $\mathbf{4 0}$ & None & \\
\hline Mean age $=\mathbf{3 2 . 5}$ & \\
\hline
\end{tabular}

Table 2: Gestational age.

\begin{tabular}{|c|c|c|}
\hline & Number & \multirow{4}{*}{ Mean $=\mathbf{3 2 . 8}$} \\
\hline$<12$ weeks & 1 & \\
\hline 13-24 weeks & 3 & \\
\hline 25-40 weeks & 96 & \\
\hline
\end{tabular}

Table 3: Course and mode of delivery.

\begin{tabular}{|lll|}
$\begin{array}{l}\text { Mode of } \\
\text { delivery }\end{array}$ & $\begin{array}{l}\text { Preterm } \\
\text { pregnancy }\end{array}$ & $\begin{array}{l}\text { Term } \\
\text { pregnancy }\end{array}$ \\
\hline NVD & 14 & 10 \\
\hline LSCS & 13 & 34 \\
\hline Total & 27 & 44 \\
\hline
\end{tabular}

NVD=Normal vaginal delivery; LSCS=Lower segment caesarean section

Table 4: Neonatal outcome.

\begin{tabular}{|llll|} 
Symptoms & $\begin{array}{l}\text { APGAR } \\
\text { score }\end{array}$ & $\begin{array}{l}\text { Gestational } \\
\text { age }\end{array}$ & Number \\
\hline Healthy & $10 / 10$ & $>36$ weeks & 67 \\
\hline RDS & $7 / 10$ & $\begin{array}{l}36 \text { weeks } 3 \\
\text { days }\end{array}$ & 1 \\
\hline $\begin{array}{l}\text { Perinatal } \\
\text { asphyxia }\end{array}$ & $4 / 10$ & 35 weeks & 1 \\
\hline $\begin{array}{l}\text { Perinatal } \\
\text { asphyxia }\end{array}$ & $4 / 10$ & 34 weeks & 1 \\
\hline
\end{tabular}

RDS=Respiratory Distress Syndrome; APGAR=Appearance,

Pulse, Grimace, Activity and Respiration

Two of our patients had abortion one at 8th week and another at 14 th week of gestation. Both the patients were managed by medical treatment. Both of them were asymptomatic for COVID-19 disease. Three of our patients had IUDs (Intra-uterine Deaths) at 22 weeks, 28 weeks and 38 weeks of gestation. All of them delivered vaginally after induction. They were asymptomatic for COVID-19 disease.

A total 27 patients delivered preterm and 44 with term pregnancy (Table 3). 47 of our patient had undergone caesarean section and 24 patients had normal vaginal delivery. Pregnancy continued in rest of patients.

Among 100 patients 88 were asymptomatic for COVID19 disease while as twelve patients had COVID-19 disease symptoms. The main complaints reported by patient related to covid-19 disease was cough and fever (9\%). All mild symptomatic patients were managed conservatively with high protein diet, multivitamin supplementation, regular monitoring of vitals, fluid-electrolyte balance and prophylactic antibiotic therapy. Two patients developed severe covid-19 pneumonia with ARDS and were shifted to ICU. One patient was postnatal (caesarean section) and developed severe symptoms on 7 th post-operative day and another patient was antenatal with 24-week gestation with USG documented anhydramnios. Both were intubated, however due to multi-organ dysfunction, both the patients expired after 20 days of illness. One among the deceased patient received IL-6 inhibitor Tocilizumab 400mg IV one dose during her ICU stay.

All neonates were subjected to RT-PCR with none producing positive results. All the new born infants were healthy except three ( 2 with perinatal asphyxia; 1 with respiratory distress syndrome) and were shifted to NICU for further management (Table 4). Breast feeding was started immediately after delivery however mothers were asked to avoid coughing or sneezing on the baby while feeding and follow hand hygiene. A fluid-resistant surgical face mask was mandatory while feeding or caring for the baby. Strict adherence to hand washing and use of sanitizer was encouraged.

\section{DISCUSSION}

Corona viruses cause illness ranging in severity from the common cold to severe respiratory illness and death. Pregnant women are considered a high-risk group because of concerns about the effect of covid-19 on them during and after pregnancy, and on their neonates. ${ }^{14}$

Normal pregnancy has been proposed to be state of physiological activation of innate limb of immune response. Pregnant women with acute infection were reported to display a more activated phenotype. ${ }^{15}$ This study aimed to find the symptomatology, clinical courses and outcomes of pregnant women with COVID-19 disease, and to assess the vertical transmission potential of COVID-19 in pregnancy. 
$75 \%$ of our patients aged between 30 to 40 years with mean age of 32.5 years. 44 of them were primigravidae while as 56 were multigravidae. The main complaints reported by patient related to covid-19 disease was cough and fever. Our results were comparable to the study done in China June 2020 with median age 31 years;52\% of their patients were nulliparous. The most common symptoms reported by the study were fever $(75 \%)$ and cough $(73 \%) .{ }^{16}$

$27 \%$ of our patients delivered preterm and $44 \%$ with term pregnancy. Caesarean section was done in $47 \%$ patients in our study for one or the other reason while as $24 \%$ delivered normally through vaginal delivery. The study done by Ferrazzi et al reported the caesarean rate for women with confirmed COVID-19 infection up to $42.9 \% .^{17}$ The rate has been reported to as high as $91-92 \%$ in other studies. ${ }^{18,19}$

All neonates were subjected to RT-PCR with none producing positive results. Breast feeding was started immediately after delivery however mothers were asked to avoid coughing or sneezing on the baby while feeding. A fluid-resistant surgical face mask was mandatory while feeding or caring for the baby.

An early study by Chen et al tested for SARS-CoV-2 on neonatal throat swabs of eight newborns and breast milk samples of three mothers, and no positive results were reported..$^{20}$ A US study of 43 women had no confirmed cases of COVID-19 detected in neonates upon initial testing on the first day of life. ${ }^{21}$ Similarly, a systematic review of 41 pregnancies in which the majority was delivered by CS, found no clinical signs of vertical transmission. ${ }^{18}$ An Italian study of 42 women, 24 of which gave birth vaginally, observed 2 early neonatal cases of COVID-19. However, they concluded that one was likely due to cross-contamination and the other due to early neonatal infection, but they could not entirely exclude the possibility of intrapartum transmission. In conclusion, they felt that vaginal delivery was associated with a low intrapartum risk of transmission. ${ }^{22}$

The main risk for new born infants is the close contact during breast feeding with COVID-19 positive mother who is likely to shed infective airborne droplets. ${ }^{23}$ Till date, the benefits of breastfeeding seem to outweigh any potential risks of transmission of the virus through breast milk. $^{24}$

\section{Limitations of study}

This study included a smaller number of patients and had a shorter follow-up period. For proper validation of these conclusions, a long-term prospective clinical study with large sample size and longer follow-up is required. In addition, further studies need to be done with the aim to answer some of the questions in relation to intra-partum management and risk of congenital infections.

\section{CONCLUSION}

Appropriate and timely management of COVID-19 positive pregnant women is a principle for safe motherhood and healthy offspring in times of global pandemic. We encourage the breast feeding immediately after delivery as benefits overweigh any potential risks of virus transmission if any. COVID-19 in new-borns born to infective mothers is uncommon. However further studies need to be done with the aim to answer some of the questions in relation to intra-partum management and risk of congenital infections.

\section{Funding: No funding sources}

Conflict of interest: None declared

Ethical approval: The study was approved by the Institutional Ethics Committee

\section{REFERENCES}

1. WHO.Summary of probable SARS cases with onset of illness from 1 November 2002 to 31 July 2003. Available at: https://www.who.int/csr/sars/country/ table2004_04_21/en/. Accessed on 16th April, 2020.

2. Hui DS, EIA, Madani TA, Ntoumi F, Kock R, Dar O et al. The continuing 2019-nCoV epidemic threat of novel coronaviruses to global health - the latest 2019 novel coronavirus outbreak in Wuhan, China. Int $\mathbf{J}$ Infect Dis. 2020;91:264-6.

3. WHO. WHO Director-General's remarks at the media briefing on 2019-nCoV on 11 February 2020. Available at: https://www.who.int/dg/speeches/ detail/whodirector-general-s-remarks-at-the-mediabriefing-on-2019-ncov-on-11february-2020.

Accessed on 16th April, 2020.

4. Scottish Intercollegiate Guidelines Network. Implementation Support. Implementation Support. Available at: https://www.sign.ac.uk/ implementation-support.html. Accessed on 15th July 2019.

5. Al-Tawfiq JA. Middle East Respiratory Syndrome Coronavirus (MERS-CoV) and COVID-19 infection during pregnancy. Travel Med Infect Dis. 2020; Available at: https://www.ncbi.nlm.nih.gov/ pmc/artic les/PMC71 18624. Accessed on 26th May, 2020.

6. Dashraath P, Jeslyn W, Karen MXL, Lim ML, Li S, Biswas A, et al. Coronavirus disease 2019 (COVID19) pandemic and pregnancy. Am J Obstet Gynecol. 2020; 222(6):521-31.

7. Liu W, Wang Q, Zhang Q, Chen L, Chen J, Zhang B, et al. Coronavirus disease 2019 (COVID-19) during pregnancy: A case series. Preprints 2020. 2020020373.

8. Chen H, Guo J, Wang C, Luo F, Yu X, Zhang W, et al. Clinical characteristics and intrauterine vertical transmission potential of COVID-19 infection in nine pregnant women: a retrospective review of medical records. Lancet. 2020;395:809-15. 
9. Zhu H, Wang L, Fang C, Peng S, Zhang L, Chang G, et al. Clinical analysis of 10 neonates born to mothers with 2019-nCov pneumonia. Transl Pediatr. 2020;9:51-60.

10. Liu Y, Chen H, Tang K, Guo Y. Clinical manifestations and outcome of SARS-CoV-2 infection during pregnancy. Journal of Infection. 2020.

11. Zhang L, Jiang Y, Wei M, Chen BH, Zhou XC, Li J, et al. Analysis of the pregnancy outcomes in pregnant women with COVID-19 in Hubei Province. Zhonghua Fu Chan Ke Za Zhi. 2020;55:166.

12. Lei D, Wang C, Li C, Fang C, Yang W, Chang B, et al. Clinical characteristics of COVID-19 in pregnancy: analysis of nine cases. Chin J Perinat Med. 2020;23(03):159-65.

13. Yan J, Guo J, Fan C, Juan J, Yu X, Li J, et al. Coronavirus disease 2019 (COVID-19) in pregnant women: a report based on 116 cases. Am J Obstet Gynecol. 2020.

14. Cabinet Office. Guidance. Staying alert and safe (social distancing). Coronavirus (COVID-19) Guidance and support. Updated 22 May 2020. Available at: https://www.gov.uk/government/ publications/staying-alert-and-safe-socialdistancing/staying-alert-and-safe-social-distancing. Accessed on 24th May, 2020.

15. Naccasha N, Gervasi MT, Chaiworaponga $T$. Phenotype and metabolic characteristics of monocytes and granulocytes in normal pregnancy and maternal infection. Am J Obstet. Gynaecol. 2001;185;1118-23.

16. Clinical Characteristics of Pregnant Women with COVID-19 in Wuhan, China. The New England J Med. 2020;382:e100.

17. Ferrazzi EM, Frigerio L, Cetin I. COVID-19 obstetrics task force, Lombardy, Italy: Executive management summary and short report of outcome. Int J Gynaecol Obstet. 2020b;149(3):377-8.
18. Di Mascio D, Khalil A, Saccone G. Outcome of Coronavirus spectrum infections (SARS, MERS, COVID 1 -19) during pregnancy: a systematic review and meta-analysis. Am J Obstet Gynecol MFM. 2020;100107.

19. Zaigham M, Andersson O. Maternal and perinatal outcomes with COVID-19: A systematic review of 108 pregnancies. Acta Obstet Gynecol Scand. 2020.

20. Chen H, Guo J, Wang C, Luo F, Yu X, Zhang W et al. Clinical characteristics and intrauterine vertical transmission potential of COVID-19 infection in nine pregnant women: A retrospective review of medical records. Lancet. 2020;395(10226):809-15.

21. Breslin N, Baptiste C, Gyamfi-Bannerman C. COVID-19 infection among asymptomatic and symptomatic pregnant women: Two weeks of confirmed presentations to an affiliated pair of New York City hospitals. Am J Obstet Gynecol MFM. 2020;100118.

22. Ferrazzi E, Frigerio L, Savasi V. Vaginal delivery in SARS-CoV-2 infected pregnant women in Northern Italy: a retrospective analysis. BJOG. 2020a.

23. Davanzo R, Moro G, Sandri F, Agosti M, Moretti C, Mosca F. Breast feeding and coronavirus disease2019: Ad interim indications of the Italian Society of Neonatology endorsed by the Union of European Neonatal \& Perinatal Societies. Matern Child Nutr. 2020:e13010.

24. FIGO. Safe motherhood and COVID. 2020. Available at: https://www.figo.org/safe-motherhood-and-covid19. Accessed on 14th May 2020.

Cite this article as: Naseer S, Andrabi SU, Andrabi SI, Tabasum H. Management of pregnant women in times of COVID-19 our experience from Kashmir valley. Int J Reprod Contracept Obstet Gynecol 2021;10:1379-83. 